\title{
Detection of flashing temperature spots of dry friction interface by means of infrared radiometer
}

\author{
by Y. Okamoto ${ }^{1}$, T. Inagaki ${ }^{2}$, C. Liu ${ }^{2}$, K. Miyata ${ }^{3}$ \\ 1 Towa University, 12-1111, Ichimiya-Gakuen, Shimonoseki City, Yamaguchi Pref., Japan, 751 \\ 2 Ibaraki University, 4-12-1, Nakanarusawa-machi, Hitachi City, Ibaraki Pref., Japan, 316 \\ ${ }^{3}$ Oiless Corporation, 8, Kirihara-machi, Fujisawa City, Kanagawa Pref. Japan, 225
}

\begin{abstract}
An experimental study of detecting a spot temperature of the dry friction interface was conducted by means of infrared radiometry. The radiation temperature distribution of the plastic dry friction interface was displayed on the CRT of the infrared radiometer (IR). The radiation temperature distribution of the reciprocating interface $T$, and the friction coefficient $\mu$ were continuously measured. The thermal behavior of the excess hot-spot temperature area of the friction interface under heavy wear condition showed that the time-dependent fluctuation of the temperature and friction coefficient was caused by the generation process of the deposited wear powder in the interface.
\end{abstract}

\section{Introduction}

A tribological surface under relative motion is widely used in bearing and sealing elements to eliminate the friction force of the moving interface. The friction force at the interface produces heat generation and temperature rise [1]. The excess heat generation of the dry friction interface under heavy wear condition increases the temperature and the friction force [2]. The temperature of the friction interface under heavy wear condition (,flashing temperature spot") becomes larger than that of the normal friction condition and, as already reported by Bowden et al [3], causes the temperature to rise of several hundred degrees centigrade.

Those phenomena play an important role in the life evaluation of tribological components, such as rupture, seizing, melt-down and wear. In order to analyze the dry friction interface, the point temperature near the surface has been generally measured by thermocouples. Recently, the temperature distribution of the hot spot of the rotating interface was measured by Okamoto and Sato et al $[4,5]$ using the IR. In this paper, an experimental study was reported to visualize and analyze thermal and dry friction behavior of the reciprocating interface of plastic materials under heavy wear condition by means of the infrared radiometer

\section{Test apparatus and experimental procedure}

A schematic illustration of the test apparatus is shown in figure 1. The apparatus consists of: stationary pad, sliding plate, friction force measurement unit, thermocouple unit and infrared radiometer. The upper cubic stationary pad is surmounted by the reciprocating sliding plate. The tribological material of the used dry friction pad and plate is polyoxymethylene (POM). The sliding velocity $V$ was regulated by the sliding motor. The normal force $F$ was adjusted by the length of the overhanging lever of the weight. The friction coefficient $\mu$ was measured by the friction force measurement unit [5].

The temperature distribution of the stationary pad was measured by Chromel and Alumel thermocouples embedded at depths of $2.3 \mathrm{~mm}$. The remote-sensing infrared camera was installed in the upward side of the sliding pad. The radiation temperature distribution was measured by means of the infrared radiometer using a $\mathrm{Hg}$-Cd-Te sensor which detected in the 8 to $13 \mu \mathrm{m}$ wavelengthband.

Table 1 shows physical properties of the tested dry-friction POM material. Table 2 illustrates several experimental conditions in terms of sliding velocity $V$ and normal force $F$. Measurements were performed of normal force $F$, friction force $\mu F$, sliding velocity $V$ and temperatures (by thermocouples) at constant time intervals after start up. Total operation time was 60 minutes. 


\section{Experimental results}

\subsection{Calibration of radiation temperature and uncertainty of measurement}

Generally, the radiation temperature Ts', measured by means of the infrared radiometer, is influenced by the radiation reflection from surrounding surfaces and does not coincide with the real temperature of the test piece Ts. So it is necessary to calibrate the radiation temperature to the real temperature Ts. Figure 2 shows the calibration correlation between the radiation temperature Ts, and the real temperature Ts. The radiation temperature Ts' is smaller than the real temperature Ts in the case when Ts is larger than the environment temperature Ta [6]. The emissivity $\varepsilon_{\mathrm{s}}$ of the POM material is found to be 0.82 in the temperature range from 283 to 400K.

Generally, the radiation temperature measured by means of the infrared radiometer includes an error. Applying the uncertainty analysis of ANSI/ASME PTC 19.1-1985, the relative uncertainty level of the temperature Ts and emissivity $\varepsilon_{s}$ were 3 and $5 \%$ respectively [6].

\subsection{Thermograms of friction interface}

Two thermograms of the friction interface are shown in figure 3 for the combination of POM and POM materials at a pressure of $0.54 \mathrm{~N} / \mathrm{mm}^{2}$ and velocity of $0.1 \mathrm{~m} / \mathrm{s}$. The radiation temperature distribution with two peaks is observed at both sides of the sliding interface after $\tau=1 \mathrm{~min}$. The temperature distribution with one peak at the center of the sliding interface is observed after $\tau=20 \mathrm{~min}$. lit was found that the center area of one peak was scratched and damaged by the temperature rise and erosion.

Figure 4 shows the thermograms of the friction interface for a pressure of $0.33 \mathrm{~N} / \mathrm{mm}^{2}$ and velocity of $0.3 \mathrm{~m} / \mathrm{s}$. The radiation temperature distribution with two peaks is observed after $\tau=1 \mathrm{~min}$. And the temperature distribution with one peak at the center position is observed after $\tau=20 \mathrm{~min}$. The temperature distribution of the interface gets back to two peaks after $\tau=30 \mathrm{~min}$ and decreases from $365 \mathrm{~K}$ at the two peaks to $345 \mathrm{~K}$ at one peak. The temperature of the friction interface from two peaks to one peak is periodically fluctuating at the interval of 10 to 15 minutes. After the test, we observed that the interface was scratched on the whole area and scuffed on the center area which produced the scaly power by the heavy wear.

Figure 5 shows the thermograms of the friction interface for a pressure of $1.08 \mathrm{~N} / \mathrm{mm}^{2}$ and velocity of $0.3 \mathrm{~m} / \mathrm{s}$. The radiation temperature distribution with two peaks is also observed after $\tau=1 \mathrm{~min}$ and increases during operation. The temperature distribution of the interface becomes trapezoidal and is over $380 \mathrm{~K}$ after $\tau=6 \mathrm{~min}$. Few hot temperature streaks at the temperature of $388-393 \mathrm{~K}$ are observed under heavy wear condition. it is clear that the most heavy wear occurs on the whole area of the sliding interface. After the test, it is observed that the interface is scratched and scuffed on the whole area which produces the scaly power by the most heavy wear.

Figure 6 and 7 show respectively the surface radiation temperature distribution Ts'(x) across the sliding surface and the transient temperature $T$ s and friction coefficient $\mu$ pressure of $0.54 \mathrm{~N} / \mathrm{mm}^{2}$ and velocity of $0.1 \mathrm{~m} / \mathrm{s}$. The temperature distribution with two peaks at both sides of the sliding interface is increasing and is $350 \mathrm{~K}$ after $\tau=15 \mathrm{~min}$. After that, the temperature distribution with one peak is increasing and gets to $365 \mathrm{~K}$. On the other hand the thermocouple temperature is gradually increasing by the initial adaptation. After 20 minutes, the temperature and friction coefficient $\mu$ becomes uniform after $20 \mathrm{~min}$ by the adaptation process.

Figure 8 and 9 show respecively the surface radiation temperature distribution $\operatorname{Ts}^{\prime}(x)$ and the transient temperature Ts and friction coefficient $\mu$ for a pressure of $0.33 \mathrm{~N} / \mathrm{mm}^{2}$ and velocity of $0.30 \mathrm{~m} / \mathrm{s}$. The temperature distribution with two peaks is observed and the interface temperature is $358 \mathrm{~K}$ after $\tau=41 \mathrm{~min}$. The temperature with one peak is increasing and is $362 \mathrm{~K}$ after $\tau=15 \mathrm{~min}$. It is clear that the temperature and friction coefficient $\mu$ are fluctuating at intervals of 10 to 15 minutes. The periodical fluctuation is supposed to be caused by the deposition of the wear powder and its heat storage at one peak period and the release of the powder and its heat release at two peaks by the heavy wear.

Figure 10 and 11 show respectively the surface radiation temperature distribution $T s^{\prime}(x)$ and the transient temperature Ts and friction coefficient $\mu$ for a pressure of $1.08 \mathrm{~N} / \mathrm{mm}^{2}$ and velocity of $0.30 \mathrm{~m} / \mathrm{s}$. The temperature distribution with two peaks is increasing and is $360 \mathrm{~K}$ after $\tau=3 \mathrm{~min}$. The temperature becomes trapezoidal and is $380 \mathrm{~K}$ in maximum after $\tau=4 \mathrm{~min}$, because of the presence of the most heavy wear streaks. At the same time, the temperature of the thermocouple is over $370 \mathrm{~K}$ and the friction coefficient $\mu$ is fluctuating by the generation of the most heavy wear streaks. 
Table 3 represents the temperature rise $\Delta T$ and friction coefficient $\mu$ for several experimental conditions. Generally, the temperature rise $\Delta \mathrm{T}$ and friction coefficient $\mu$ become large with increase in values of $P V$ and stroke $S$.

\section{Conclusion}

The tribological and thermal behaviors of the dry reciprocating interface of POM materials was measured and analyzed by means of the infrared radiometer. The temperature of the friction interface is increasing during the duration of the operation. The radiation temperature distribution of the sliding interface changes from the two peaks to one peak at intervals of 10 to 15 minutes. The temperature of the sliding plate and the friction coefficient $\mu$ is fluctuating because of the repeating production and releasing process of the wear powder under heavy wear condition.

\section{REFERENCES}

[1] KIMURA (K.) -Introduction to Tribology, Yokendo, (1994), p.31-50.

[2] OKAMOTO (Y.) -Remote-sensing Infrared Thermal Measurement Technique, Corona Pub., (1994), p.26-36.

[3] BOWDEN (F. P.) and THOMAS (P.) -The Friction and Lubrication of Solid, Oxford, (1954), p.31-35.

[4] OKAMOTO (Y.) INAGAKI (T.), ISHII (T.) KUROKAWA (T.) -Basis and Its Practice of Thermal Image Techniques, ibid, (1), (1995), p.96-99.

[5] SATO (M.), MIYAMOTO (K.), INAGAKI (T.), OKAMOTO (T.) -Study on Thermal and Wear Phenomena, Visual Information, (1996), p.203-208.

[6] ASME, -Test Cods Supplement on Instrumentation, Measurement, Uncertainty, (1985), p.120. 


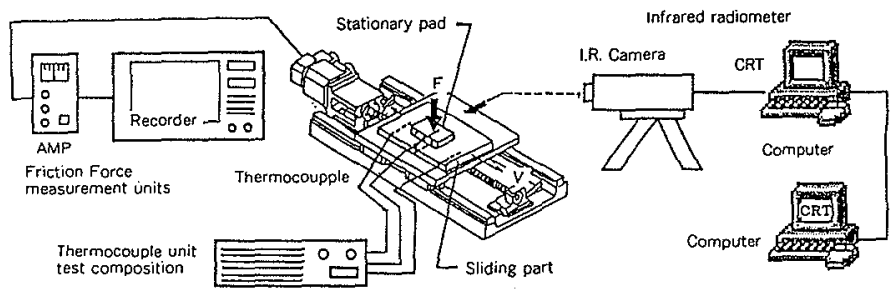

Fig.1 Experimental apparatus

Table 1 Physical properties of POM

\begin{tabular}{lccc}
\hline $\begin{array}{l}\text { Mechanical and } \\
\text { Physical Froperties }\end{array}$ & $\begin{array}{c}\text { ASTM } \\
\text { Test method }\end{array}$ & Units & $\begin{array}{c}\text { POM } \\
\text { (Poly-oxymethylene) }\end{array}$ \\
\hline Special gravity & $\mathrm{D} 792$ & - & 1.41 \\
Thensile strength & $\mathrm{D} 638$ & $\mathrm{~N} / \mathrm{mm}^{2}$ & 51.0 \\
Elongation & $\mathrm{D} 638$ & $\%$ & 25.0 \\
Flexural strength & $\mathrm{D} 790$ & $\mathrm{~N} / \mathrm{mm}^{2}$ & 76.5 \\
Impact strength (lzod) & $\mathrm{D} 256$ & $\mathrm{~J} / \mathrm{m}^{2}$ & 58.8 \\
Elastics modulus & $\mathrm{D} 747$ & $\mathrm{~N} / \mathrm{mm}^{2}$ & 2.650 \\
Compressive strength (1\%) & $\mathrm{D} 695$ & $\mathrm{~N} / \mathrm{mm}^{2}$ & 21.2 \\
Rockwell Hardness & $\mathrm{D} 785$ & $\mathrm{HRM}$ & 72 \\
Thermal diffusivity & - & $\mathbf{m}^{2} / \mathrm{sec}$ & $1.13 \times 10^{-7}$ \\
Specific heat & - & $\mathrm{kJ} /(\mathrm{kg} \cdot \mathrm{K}$ ) & 1.47 \\
Thermal conductivity & - & $\mathrm{W} /(\mathbf{m} \cdot \mathrm{K})$ & 0.232 \\
\hline
\end{tabular}

Table 2 Test conditions

\begin{tabular}{ccc}
\hline Test No. & $\begin{array}{c}\text { Pressure } \\
\left(\mathrm{N} / \mathrm{mm}^{2}\right)\end{array}$ & $\begin{array}{c}\text { Velocity } \\
(\mathrm{m} / \mathrm{sec})\end{array}$ \\
\hline 1 & 0.22 & 0.10 \\
2 & 0.33 & 0.10 \\
3 & 0.54 & 0.10 \\
4 & 1.08 & 0.10 \\
5 & 0.22 & 0.30 \\
6 & 0.33 & 0.30 \\
7 & 0.54 & 0.30 \\
8 & 1.08 & 0.30 \\
9 & 0.22 & 0.06 \\
10 & 0.33 & 0.06 \\
11 & 0.54 & 0.06 \\
12 & 1.08 & 0.06 \\
\hline
\end{tabular}

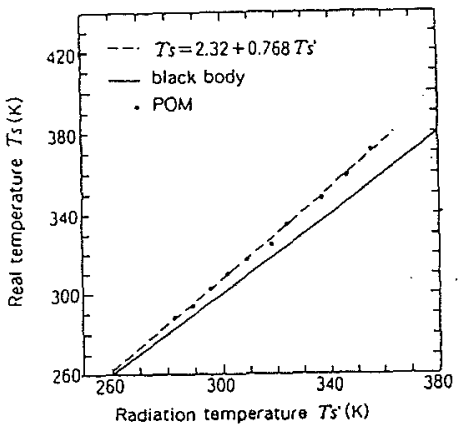

Fig. 2 Calibration correlation between radiation temperature and real temperature of POM material
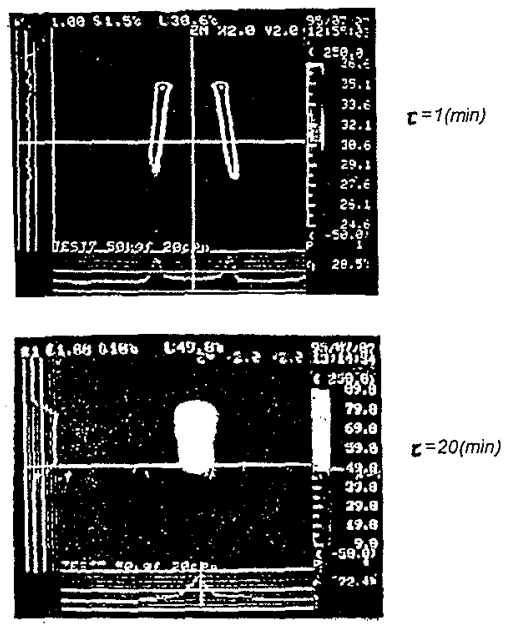

Fig.3 Thermograph of radiation temperature of reciprocating interface $\left(P=0.54 \mathrm{~N} / \mathrm{mm}^{2}, V=0.10 \mathrm{~m} / \mathrm{s}, S=150 \mathrm{~mm}\right)$ 

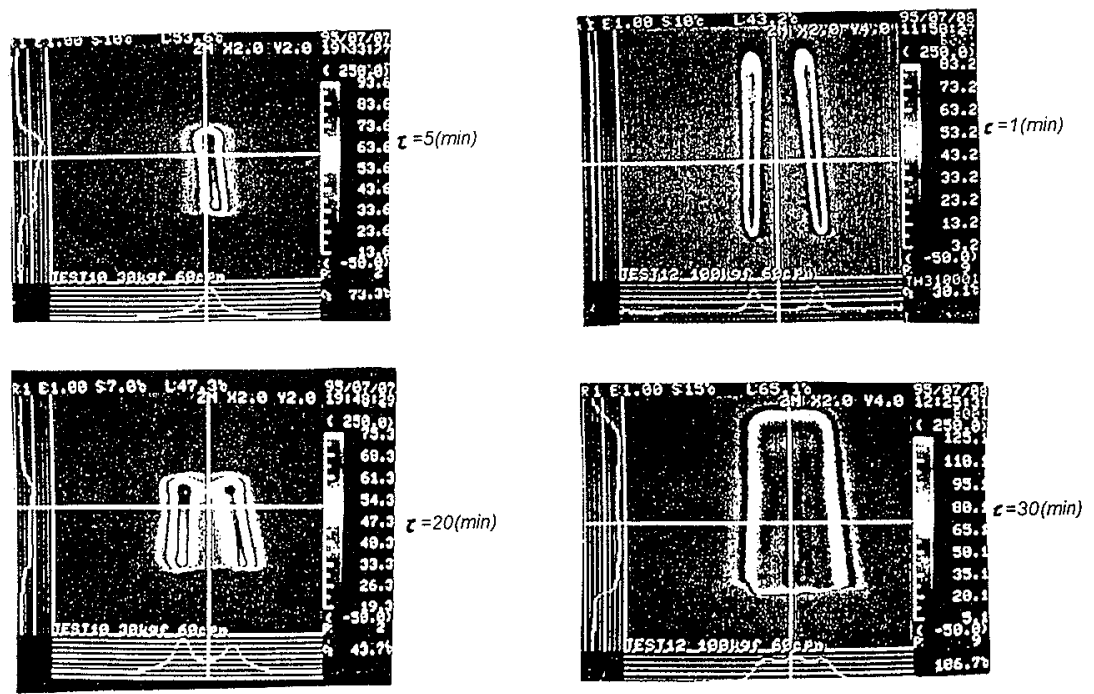

Fig.4 Thermograms of reciprocating interface $\left(P=0.33 \mathrm{~N} / \mathrm{mm}^{2}, V=0.30 \mathrm{~m} / \mathrm{s}, S=150 \mathrm{~mm}\right)$

Fig. 5 Thermograms of reciprocating interface $\left(P=1.08 \mathrm{~N} / \mathrm{mm}^{2}, V=0.30 \mathrm{~m} / \mathrm{s}, S=150 \mathrm{~mm}\right)$

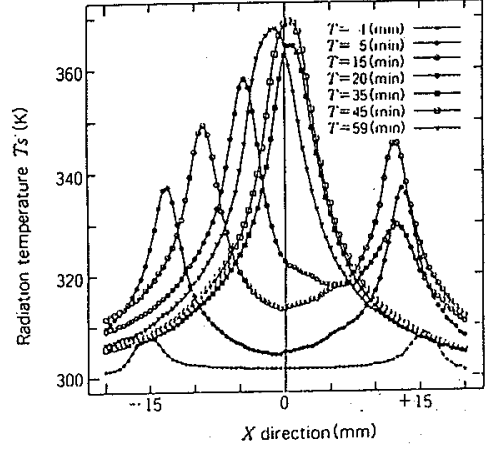

Fig. 6 Surface radiation temperature distribution of sliding plate $\left(P=0.54 \mathrm{~N} / \mathrm{mm}^{2}, V=0.10 \mathrm{~m} / \mathrm{s}, \mathrm{S}=150 \mathrm{~mm}\right)$

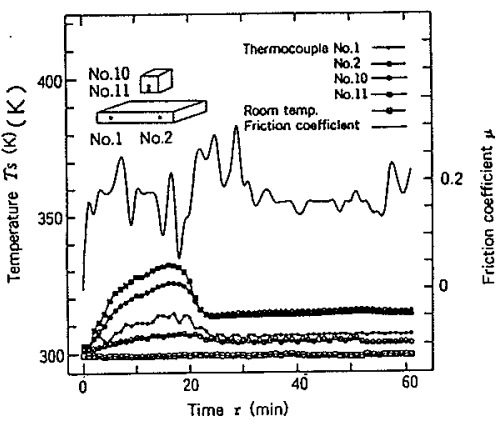

Fig.7 Transient temperature and friction coefficient of sliding plate $\left(P=0.54 \mathrm{~N} / \mathrm{mm}^{2}, V=0.10 \mathrm{~m} / \mathrm{s}, S=150 \mathrm{~mm}\right)$ 


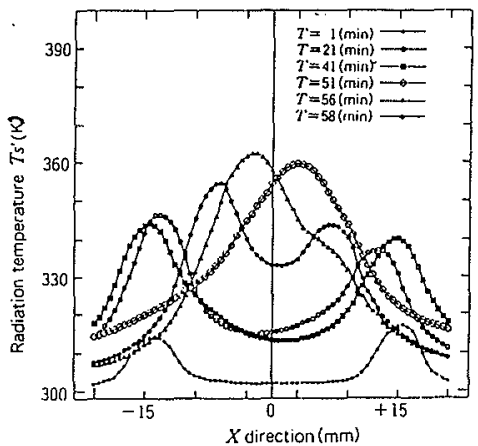

Fig. 8 Surface radiation temperature distribution of sliding plate $\left(P=0.33 \mathrm{~N} / \mathrm{mm}^{2}, V=0.30 \mathrm{~m} / \mathrm{s}, S=150 \mathrm{~mm}\right)$

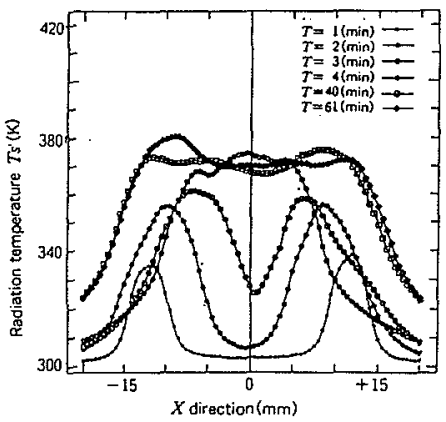

Fig.10 Surface radiation temperature distribution of sliding plate $\left(P=1.03 \mathrm{~N} / \mathrm{mm}^{2}, V=0.30 \mathrm{~m} / \mathrm{s}, \mathrm{S}=150 \mathrm{~mm}\right)$

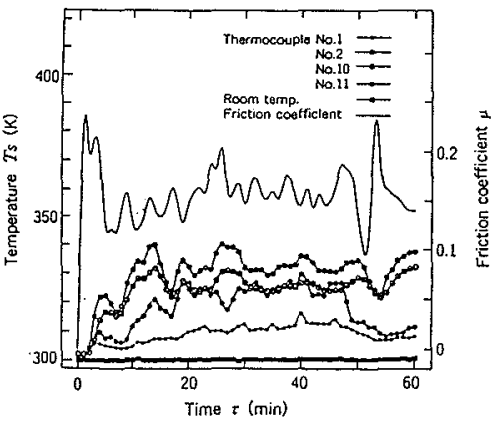

Fig.9 Transient temperature and friction coefficient of sliding interface $\left(P=0.33 \mathrm{~N} / \mathrm{mm}^{2}, V=0.30 \mathrm{~m} / \mathrm{s}, S=150 \mathrm{~mm}\right)$

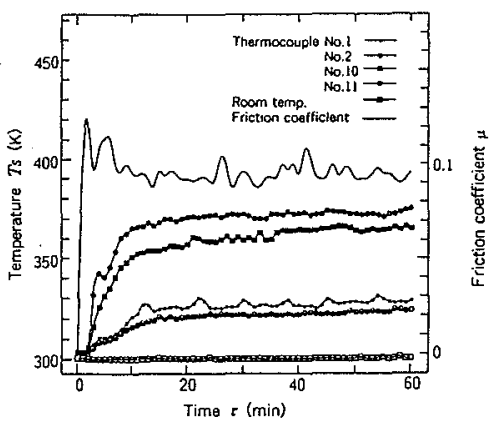

Fig.11 Transient temperature and friction coefficient of sliding interface $\left(P=1.08 \mathrm{~N} / \mathrm{mm}^{2}, V=0.30 \mathrm{~m} / \mathrm{s}, \mathrm{S}=150 \mathrm{~mm}\right)$

Table 3 Temperature rise $\Delta \mathrm{T}$ and friction coefficient $\mu$

\begin{tabular}{|c|c|c|c|c|c|}
\hline No. & $\begin{array}{l}\text { PV Values } \\
\left(\mathrm{N} / \mathrm{mm}^{2} \cdot \mathrm{m} / \mathrm{s}\right)\end{array}$ & $\begin{array}{l}\text { Temperature } \\
\text { Rise } \\
T s^{\prime} \max . \\
(\mathrm{K})\end{array}$ & $\begin{array}{c}\text { Temperature } \\
\text { Variation } \\
\Delta T s^{\prime} \text { vari. } \\
\text { (K) }\end{array}$ & $\begin{array}{l}\text { Variation } \\
\text { Rate } \\
\Delta T^{\prime} \text { rate } \\
(\mathscr{Q})\end{array}$ & $\begin{array}{l}\text { friction } \\
\text { coefficient } \\
\mu\end{array}$ \\
\hline 1 & 0.021 & 89.9 & 31.45 & 112.7 & 0.224 \\
\hline 2 & 0.033 & 104.8 & 27.65 & 98.4 & 0.252 \\
\hline 3 & 0.054 & 111.6 & 41.05 & 142.5 & 0.180 \\
\hline 4 & 0.108 & 123.8 & 58.40 & 192.7 & 0.235 \\
\hline 5 & 0.063 & 79.3 & 35.90 & 130.5 & 0.199 \\
\hline 6 & 0.099 & 96.3 & 38.85 & 133.0 & 0.163 \\
\hline 7 & 0.162 & 109.2 & 40.75 & 144.5 & 0.134 \\
\hline 8 & 0.224 & 119.4 & 33.00 & 107.1 & 0.098 \\
\hline 9 & 0.072 & 43.9 & 9.75 & 31.4 & 0.179 \\
\hline 10 & 0.036 & 79.5 & 23.90 & 76.1 & 0.216 \\
\hline 11 & 0.022 & 91.5 & 32.45 & 108.5 & 0.234 \\
\hline 12 & 0.072 & 106.8 & 34.60 & 118.5 & 0.218 \\
\hline
\end{tabular}

